\title{
Bladder cancer in patients with spina bifida: observation from an adult clinic
}

\author{
Mar Meléndez ${ }^{1} \cdot$ Anna Maroto $^{2} \cdot$ Tamara Illescas $^{2} \cdot$ Marta Allué $^{3} \cdot$ Luis Castro $^{3} \cdot$ Elena Carreras $^{2} \cdot$ Ampar Cuxart $^{1}$
}

Received: 16 February 2017 / Revised: 28 February 2018 / Accepted: 5 March 2018

(c) International Spinal Cord Society 2018

\begin{abstract}
Study design Retrospective descriptive study of patients with spina bifida and bladder cancer.

Objectives To compare the medical characteristics of patients diagnosed with spina bifida and bladder cancer to those patients diagnosed with spina bifida only.

Setting Spina Bifida Clinic in Hospital Universitari Vall d'Hebron (Barcelona, Spain).

Methods Patients registered in the Spina Bifida Clinic between 1990 and 2015 and born before 1996 were included. We analyzed patients with confirmed bladder cancer. Demographic data, type of spina bifida, functional level, mode of bladder management, and risk factors for bladder cancer were compared between patients who developed bladder cancer and the rest of patients from the Clinic using the exact Fisher's test.

Results The study included 446 patients with spina bifida, all older than 20 years. From these, ten patients also presented a bladder cancer at a mean age of 36 years (range 27-43), and with a higher proportion of mid-lumbar functional level (L3 in six out of ten patients). Eight of them were female. A wide variability of presenting symptoms was observed with locally advanced disease in nine cases. The median survival time was 4 months.

Conclusions Despite the advances in surgical and medical treatments, the prognosis of bladder cancer in patients with spina bifida is still poor. Screening tools are needed to improve the outcomes.
\end{abstract}

\section{Introduction}

All spina bifida patients (SB) have neurogenic bladder. The new accomplishments in the management and surgical techniques for the preservation of renal function have increased the life expectancy of these patients [1]. The introduction of the clean intermittent catheterization (CIC) $[2,3]$ has changed the renal function prognosis and the current urological management is mainly based on either $\mathrm{CIC}$ and associated anticholinergic agents or surgical procedures on the bladder [1-4].

Ampar Cuxart

acuxart@vhebron.net

$1 \quad$ Physical Medicine and Rehabilitation. Hospital Universitari Vall d'Hebron, Universitat Autònoma de Barcelona, Barcelona, Spain

2 Maternal-Fetal Medicine, Hospital Universitari Vall d'Hebron, Universitat Autònoma de Barcelona, Barcelona, Spain

3 Urology, Hospital Universitari Vall d'Hebron, Universitat Autònoma de Barcelona, Barcelona, Spain
An association between neurogenic bladder and bladder cancer has been suggested. Some case series including spinal cord-injured patients with locally advanced presentations of bladder cancer at young age have been reported [5]. The incidence of bladder cancer for patients with spinal cord injury (SCI) varies between 0.1 and $10 \%$ [5], whereas the incidence in normal population is $0.14-0.2 \%$ o [6]. Intermittent or permanent catheterization, chronic urinary tract infections, urothelial inflammation, bladder calculi, and bladder augmentation surgery have been described as predisposing factors for bladder cancer [7, 8].

The Spina Bifida Clinic at the Hospital Universitari Vall d'Hebron provides comprehensive and lifelong care for patients with SB. The aim of this study is to present our experience with SB patients who developed bladder cancer and to compare them with the rest of the patients from the Clinic.

\section{Methods}

This is a retrospective descriptive study of SB patients from the Spina Bifida Clinic at the Hospital Universitari Vall 
d'Hebron in Barcelona, Spain. The study was approved by the Research Ethics Committee of the Hospital Universitari Vall d'Hebron.

All patients with SB, registered in the database of the Spina Bifida Clinic from 1990 to 2015, were reviewed. In the absence of complications, SB patients were regularly monitored in the Clinic once a year. Since bladder cancer typically presents in adulthood, patients under 20 years of age were excluded from the original database in order to match by age with patients with SB and bladder cancer.

Demographic data and the following variables were collected from the patients included in the study: type of SB (myelomeningocele-MMC - or closed defect), functional ambulatory level (based on prognostic grounds, the classification is: dorsal, L1-L2 or high-lumbar, L3 or mid-lumbar, L4-L5 or low-lumbar, sacral), mode of bladder management (voluntary control of sphincter, scheduled voiding, Credé maneuver, CIC, collector, indwelling catheter, vesicostomy, hemodialysis or use of diaper), and presence of risk factors for bladder cancer (recurrent urinary infections, defined as more than three episodes per year; urinary tract calculi; bladder augmentation surgery). The smoking status could not be retrieved for every patient in the Clinic thus this variable was not used for comparisons between groups.

The routine follow-up of patients with SB includes annual renovesical ultrasound. Patients who presented with relevant urinary symptoms were evaluated with cystoscopy and those with histological confirmation of bladder cancer were analyzed. We described the presenting symptoms of bladder cancer, the histological type and the stage of the bladder cancer, surgical and medical treatments and survival.

Finally, we compared the medical characteristics of patients with and without bladder cancer among those from the Spina Bifida Clinic over 20 years of age.

The exact Fisher's test (for small samples) was used to compare the categorical variables between groups. The statistical analysis was performed with the STATA 13.1 software package and a $p$ value $<0.05$ was considered statistically significant.

\section{Results}

A total of 618 patients from the Spina Bifida Clinic database were reviewed; from these, 464 patients born before 1996 were selected, $382(82.3 \%)$ with MMC, and $82(17.7 \%)$ with closed SB. Gender distribution, functional level, need of shunting, mode of bladder management, and other risk factors for bladder cancer of the selected population from the Clinic are summarized in Table 1.
Table 1 Characteristics of patients with spina bifida over 20 years of age from the Spina Bifida Clinic at the Hospital Universitari Vall d'Hebron, with and without bladder cancer

\begin{tabular}{|c|c|c|c|}
\hline & $\begin{array}{l}\text { No bladder } \\
\text { cancer }(N= \\
454)\end{array}$ & $\begin{array}{l}\text { Bladder } \\
\text { cancer }(N= \\
10)\end{array}$ & $\begin{array}{l}\text { Fisher test } \\
(p \text { value })\end{array}$ \\
\hline \multicolumn{4}{|l|}{ Gender } \\
\hline Male & 215 & 2 & \multirow[t]{2}{*}{0.11} \\
\hline Female & 239 & 8 & \\
\hline \multicolumn{4}{|l|}{ Type of spina bifida } \\
\hline Myelomeningocele & 373 & 9 & \multirow[t]{2}{*}{1.00} \\
\hline Closed spina bifida & 81 & 1 & \\
\hline \multicolumn{4}{|l|}{ Functional level } \\
\hline Dorsal & 129 & 1 & \multirow[t]{5}{*}{$<0.01$} \\
\hline High lumbar & 8 & 0 & \\
\hline Mid lumbar & 51 & 6 & \\
\hline Low lumbar & 133 & 2 & \\
\hline Sacral & 133 & 1 & \\
\hline \multicolumn{4}{|c|}{ Ventriculo-peritoneal shunt } \\
\hline Yes & 267 & 8 & \multirow[t]{2}{*}{0.09} \\
\hline No & 187 & 1 & \\
\hline \multicolumn{4}{|l|}{ Bladder management } \\
\hline Voluntary control & 40 & 0 & \multirow[t]{9}{*}{0.60} \\
\hline $\begin{array}{l}\text { Scheduled bladder } \\
\text { voiding }\end{array}$ & 43 & 2 & \\
\hline Credé & 11 & 0 & \\
\hline CIC & 184 & 5 & \\
\hline Indwelling catheters & 43 & 2 & \\
\hline Collector & 32 & 0 & \\
\hline Diaper & 62 & 0 & \\
\hline Urinary diversion & 36 & 1 & \\
\hline Hemodialysis & 3 & 0 & \\
\hline \multicolumn{4}{|l|}{ Risk factors } \\
\hline Bladder augmentation & 1 & 0 & \multirow[t]{3}{*}{0.46} \\
\hline Recurrent UTI & 57 & 10 & \\
\hline Bladder calculi & 17 & 6 & \\
\hline
\end{tabular}

We identified ten cases (2.2\%) with a histological confirmation of bladder cancer. They had been periodically monitored in the Spina Bifida Clinic with annual renovesical ultrasound; nine of them were affected with MMC and one case had a closed SB (lipomeningocele). The mean age at diagnosis was 36 years (range 27-43). At the time of diagnosis, nine patients $(90 \%)$ had locally advanced stage disease (T3 or greater, TNM classification 2010). All patients had a muscle invasive type of bladder cancer. Table 2 summarizes the information about the ten cases of SB and bladder cancer.

The exact Fisher's test showed no statistically significant differences between groups with one exception: the 


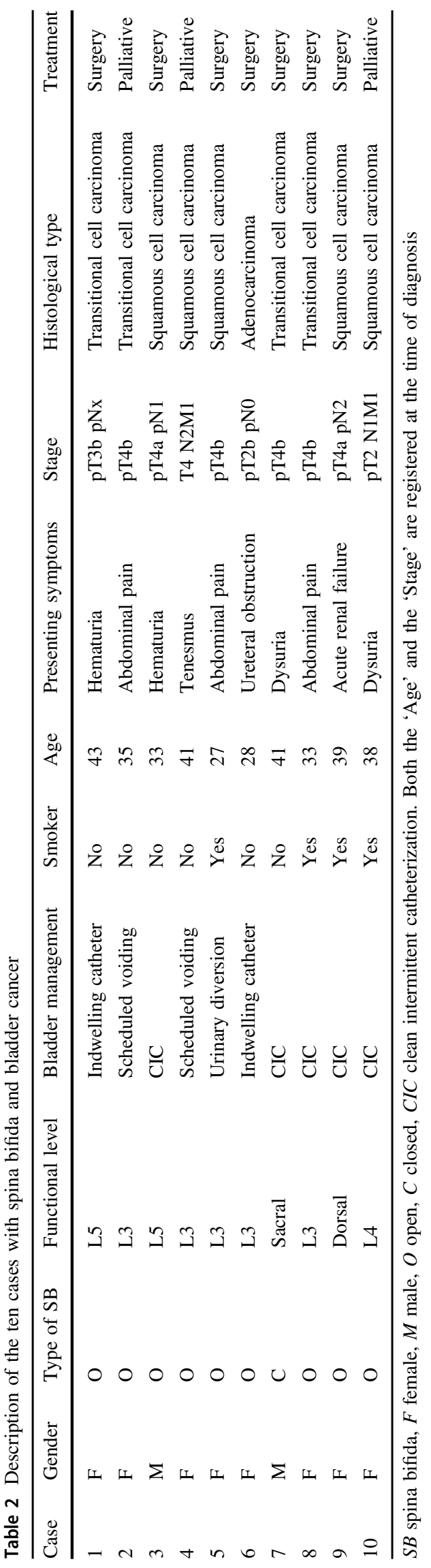

functional level in patients with bladder cancer was predominantly mid-lumbar (L3), with a $p$ value $=0.02$.

Seven patients underwent radical cystectomy with ileal conduit urinary diversion followed by adjuvant chemotherapy whereas three cases received palliative treatment due to the advanced stage of disease. Eight of the ten patients diagnosed with bladder cancer died within the first year after diagnosis. The only surviving patient at the time of the study was not tumor free. The median survival time since the diagnosis was 4 months (4-48).

\section{Discussion}

This brief report showed a poor short-term prognosis of bladder cancer in SB patients, with mild and non-specific documented symptoms.

The reported incidence of bladder cancer is similar for patients with congenital neural tube defects 2-4\% [9] compared to those with spinal cord injuries, who usually develop the cancer 18-34 years from the onset of SCI (0.1-10\%) [5]. The prevalence of bladder cancer and the age of presentation in our Spina Bifida Clinic are consistent with those data.

The proportion of each histological type in our results also matches the data previously reported in the literature, with an increased ratio of squamous cell carcinoma (50\% in our SB patients), compared to the general population (1.2-7\% of all bladder tumors) [10].

Of note is the significant higher proportion of midlumbar level (L3) found in patients with bladder cancer in our series. Previous reports described an association between dorsal and high-lumbar lesion levels and higher frequency of bladder augmentation [3]. However, most etiological theories propose the chronic irritation of the urothelium in patients with neurogenic bladder and the need of long-term catheterization as the predisposing factors to oncogenic transformation [3, 8]. Thus, the neurogenic bladder and the type of bladder management could be responsible for cancer regardless of the lesion level.

Multiple case series have been published in order to establish the relationship between bladder cancer and neurogenic diseases. The largest series reported are from patients with SCI and only short case series about SB patients with bladder cancer were reported [4, 8]. The main risk factors for bladder cancer described in this population were indwelling catheters, urinary tract infections, and bladder calculi [5, 8]. Perhaps some intrinsic features of the urothelium in SB patients could influence the presence of bladder cancer. In our series, all patients affected with bladder cancer had reported recurrent urinary tract infections. Half of them had used CIC as the mode of bladder management and two of them voided spontaneously 
(with no significant differences with the rest of our SB patients). Bladder augmentation has been regarded as a risk factor for transitional cell carcinoma [4], but this has not been reflected in our results either.

Despite the well-known association between tobacco use and transitional-cell carcinoma, only one of the four patients diagnosed with this histological type was a smoker. While this study has too few patients to detect a clear risk factor for tobacco and bladder cancer, all SB patients should be monitored and be informed of the potential risk.

In spite of the current knowledge and advances in surgical and medical treatments, the prognosis of bladder cancer in patients with SB is still poor, with a median survival of 4 months [4]. This is probably due to the aforementioned factors and to the aggressive histological types, the nonspecific clinical presentation and the wide variability of symptoms, which probably hinder an early diagnosis thus leading to an advanced stage at presentation [5]. For this reason, several authors have proposed screening cystoscopies for patients with SCI and other known risk factors (indwelling catheters used for $>10$ years, recurrent urinary tract infections, smoking status) [11]. However, the absence of additional risk factors in SB patients apparently does not exclude the risk of bladder cancer, and implementing this screening strategy in all patients would entail high personal and financial costs. On the other hand, since these tumors usually grow fast, annual cystoscopies may still miss early treatable disease.

\section{Conclusions}

Our small case series has revealed a need for further research on bladder cancer and SB. We believe screening tools should be developed and implemented to detect bladder cancer at earlier stages to promote better outcomes.

\section{Compilance with ethical standards}

Conflict of interest: The authors declare that they have no conflict of interest.

\section{References}

1. Veenboer PW, Bosch JL, van Asbeck FW, de Kort LM. Upper and lower urinary tract outcomes in adult myelomeningocele patients: a systematic review. PLoS One. 2012;7:e48399.

2. Lapides J, Diokno AC, Silber SJ, Lowe BS. Clean, intermittent self-catheterization in the treatment of urinary tract disease. J Urol. 1972;107:458-61.

3. Metcalfe P, Gray D, Kiddoo D. Management of the urinary tract in spina bifida cases varies with lesion level and shunt presence. J Urol. 2011;185(6 Suppl):2547-51.

4. Austin JC, Elliott S, Cooper CS. Patients with spina bifida and bladder cancer: atypical presentation, advanced stage and poor survival. J Urol. 2007;178:798-801.

5. Welk B, McIntyre A, Teasell R, Potter P, Loh E. Bladder cancer in individuals with spinal cord injuries. Spinal Cord. 2013;51:516-21.

6. Canadian Cancer Society's Advisory Committee on Cancer Statistics. Canadian Cancer Statistics 2010. Toronto, ON: Canadian Cancer Society; 2010.

7. West DA, Cummings JM, Longo WE, Virgo KS, Johnson FE, Parra RO. Role of chronic catheterization in the development of bladder cancer in patients with spinal cord injury. Urology. 1999;53:292-7.

8. Mirkin K, Casey JT, Mukherjee S, Kielb SJ. Risk of bladder cancer in patients with spina bifida: case reports and review of the literature. J Pediatr Rehabil Med. 2013;6:155-62.

9. Rove KO, Husmann DA, Wilcox DT, Vricella GJ, Higuchi TT. Systematic review of bladder cancer outcomes in patients with spina bifida. J Pediatr Urol. 2017;13:456.e1-456.e9.

10. Prudnick C, Morley C, Shapiro R, Zaslau S. Squamous cell carcinoma of the bladder mimicking interstitial cystitis and voiding dysfunction. Case Rep Urol. 2013;2013:924918.

11. Navon J, Soliman H, Khonsari F, Ahlering T. Screening cystoscopy and survival of spinal cord injured patients with squamous cell cancer of the bladder. J Urol. 1997;157:2109-11. 